Sharif University of Technology
Scientia Iranica
SCIENTIA
IRAN I CA
Transactions A: Civil Engineering
www.scientiairanica.com

\title{
Design and assessment of seismic resilient structures by the endurance time method
}

\author{
H.E. Estekanchi*, A. Vafai and M.Ch. Basim \\ Department of Civil Engineering, Sharif University of Technology, Tehran, P.O. Box 11155-9313, Iran. \\ Received 5 May 2015; accepted 4 August 2015
}

KEYWORDS
Earthquake
engineering;
Seismic resilience;
Endurance time
method;
Value based seismic
design;
Nonlinear dynamic
analysis.

\section{KEYWORDS}

Endurance time

method;

design;

analysis.

\begin{abstract}
A framework to calculate a quantitative measure of seismic resilience using the Endurance Time (ET) method is introduced. ET method is a response-history based analysis procedure where structures are subjected to gradually intensifying dynamic excitations and their performance is assessed based on their response at different excitation levels, reducing the required computational effort. First, a prototype hospital building is optimally designed through three distinct design philosophies: prescriptive design code, performance based design criteria, and value based seismic design method. In value based design method, the design sections of structural elements are assumed as optimization parameters and a design with minimum total cost during its lifespan is sought. For each candidate design, the damages due to probable earthquakes are estimated by the ET method and the expected cost of damages is calculated using Life Cycle Cost Analysis (LCCA). Next, the resilience of each design in continuous range of hazard intensities is compared with that of others, introducing "Resilience Curve". Although the optimization objectives in design process are not based on resiliency measures, the value based design shows the best resiliency in the case of seismic hazards. This methodology and potential benefits when considering the need for moving towards more resilient cities are discussed.

(C) 2016 Sharif University of Technology. All rights reserved.
\end{abstract}

\section{Introduction}

The resilience in cities and meanwhile optimum allocation of public resources necessitate providing structures with predictable and reliable performance in the case of natural hazards. Earthquakes are considered to be one of the most destructive and costly natural hazards that threaten cities in seismically active regions. Thus, assessment of seismic safety and performance of buildings and structural components is one of the major challenges in Earthquake Engineering. Reliability and accuracy of seismic analysis procedure is a key

*. Corresponding author. Tel.: +98 2166164212 ;

Fax: +982166014828

Email addresses: stkanchi@sharif.edu (H.E. Estekanchi); vafai@sharif.edu (A.Vafai); basim@sut.ac.ir (M.Ch.

Basim) concern in almost all seismic assessment procedures for both new and existing structures, especially in modern approaches of seismic design. Various limitations of simplified seismic analyses have increased the need for more realistic and reliable dynamic analysis procedures. Endurance Time (ET) method is a response-history based seismic assessment procedure where structures are subjected to gradually intensifying dynamic excitations and their performance is evaluated based on their response at different excitation levels correlating with specific ground motion intensities [1]. This procedure considerably reduces the required huge computational demand of a complete response history analysis while maintaining the major benefits of it, i.e. accuracy and insensitivity to model complexity. This viable advantage provides the prerequisites to directly incorporate the new age design concerns, such as life cycle cost of the structure or resiliency measures, 
in design procedure [2]. The main objective of this research is to explore the use of ET method in evaluating resiliency of a construction in quantitative terms. This work is an extension of a paper presented at the Symposia on Resilient Cities [3].

The concept of disaster resilience in communities has been introduced in recent years. The need to emphasize the preparedness of communities to recover from disasters has been confirmed in the 2005 World Conference on Disaster Reduction (WCDR). The aim is to be prepared and to be able to recover in an acceptable time from an unexpected shock in the community and meanwhile reduce its vulnerability. The overview of intuitive definitions of resiliency can be found in a work by Manyena [4]. Some frameworks are introduced to provide quantitative evaluation of resilience. These methods can be considered as complementary analysis beyond estimating losses. Resilience measures should take technical, social, and economic impacts of a disaster into account to cover the vast definition of resilience [5]. A general framework for evaluating community resilience has been introduced by Bruneau et al. [6]. They used complementary measures of resilience as reduced failure probabilities, reduced consequences of failures, and reduced time to recovery. They used four dimensions of resiliency for a system as robustness, rapidity, resourcefulness, and redundancy. Chang and Shinozuka [7] also introduced a measure of resilience that related expected losses in future disasters to a community's seismic performance objectives and implemented the method in a case study of the Memphis water delivery system.

Many uncertain parameters are involved in resilience of a construction in the case of a natural or man-made hazard. Bruneau and Reinhorn [8] tried to relate probability functions, fragilities, and resilience in a single integrated approach for acute care facilities. Cimellaro et al. [5] proposed a framework to evaluate disaster resilience based on dimensionless analytical functions related to the variation of functionality during a period of interest, including the losses in the disaster and the recovery path. Losses are described as functions of fragility of systems that are determined using multidimensional performance limit thresholds accounting for uncertainties. They implemented the method for a typical Californian Hospital building and also a hospital network considering direct and indirect losses. Their proposed framework with some modifications is used as the underlying basis of the present study.

Value based seismic design of structures using the ET method has been introduced in a work by Basim and Estekanchi [9]. In this methodology, Life Cycle Cost Analysis (LCCA) has been used in order to evaluate the performance of the structure during its lifespan in economic terms. This analysis can provide a baseline to incorporate technical, economic, and social or any other intended measures thought to be impressive in resilience of cities in design procedure. The broad concept of resilience demands a flexible design framework to employ these several criteria from various fields of expertise in design stage. LCCA demands performance assessment of the structure in multiple hazard levels. Considering the required repetitive and massive analyses in this procedure, application of ET method in combination with the concept of LCCA can provide the means to use economic concerns directly in design stage.

To demonstrate the proposed method for quantitative evaluation of the resilience by the ET method, a prototype structure of a hospital building located in Tehran is optimally designed according to 3 distinct design philosophies:

1. Iranian National Building Code (INBC) as a prescriptive design criteria;

2. FEMA-350 [10] limitations as a performance based design criteria;

3. Value based design method.

In the third design approach, it is tried to design a structure having the minimum total cost during its lifetime. The resilience of the three different designs of the structure is evaluated using the proposed method and results are compared and discussed. Reduced computational demand in ET analysis method provides the prerequisites to use optimization algorithms in design procedure. Although resiliency measures are not directly incorporated in optimization procedure here, this work is intended to pave the way towards the practical design of construction with the highest resiliency.

\section{Earthquakes and resiliency}

Cities cannot be considered resilient if they are not protected against the dangers and potential damages that may be imposed by natural hazards. Earthquakes are considered to be one of the most destructive and costly natural hazards that threaten cities. So, stability of community during and after seismic hazards is thought to have a significant impact on the resilience of cities in seismically active regions.

On this issue, resilience may have broad measures in the whole city as a body or sub-measures in individual buildings. Also, the impact of seismic hazards on a community may be studied from various points of view and also various concepts may be defined as resilience, such as time to recovery, life safety, or damage reduction. For example, "downtime" seems to be an impressive resilience measure for a hospital building or a fire station besides life safety and it 


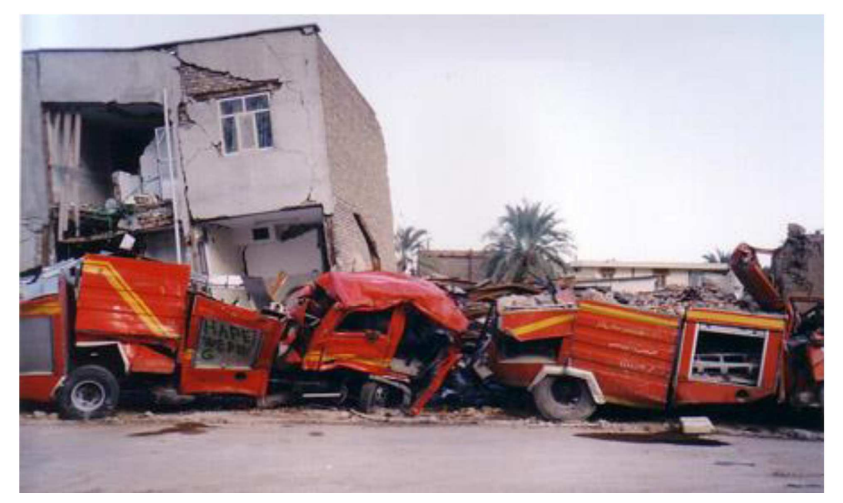

Figure 1. A fire station destroyed in Bam earthquake [11].

is wise to consider these measures with reasonable portion in design stage. Some limitations may be required for such critical facilities too. In Figure 1, a fire station, which has known role in recovery of cities, is shown that is destroyed and has obviously lost its functionality in Bam earthquake in 2003 [11]. Appropriate measures, in a quantifiable manner, seem to be required to incorporate such consequent events in earthquake engineering scope.

Incorporation of seismic resilience factors in design procedure requires mitigation from common design procedures intended to focus on a limited number of objectives such as structural performance or loss prevention to a broader one with the capability to incorporate any desired and advancing terms in priority measures among design alternatives. Codes for building design, commonly, set some minimum compliancebased standards and in performance terms, we can be confident that they will provide safe buildings, but they promise little in terms of recovery. The readily introduced methodology can provide a wider description of design target by defining the earthquake consequences, such as structural damages, loss of contents, losses due to downtime, and human injuries and fatalities in the form of quantifiable parameters. In this way, it is expected that the resultant design will perform with desired post-earthquake capabilities with manageable disruption.

\section{Concepts of endurance time method}

A reliable estimation of the damage to various structures and their compartments requires realistic evaluation of seismic response of structures when subjected to strong ground motions. This, in turn, requires the development and utilization of advanced numerical techniques using reasonably realistic dynamic modeling. While any serious development in the area of seismic resistant design has to be backed up with decent real-world experimental investigation, the type and number of decision variables are usually so diverse that

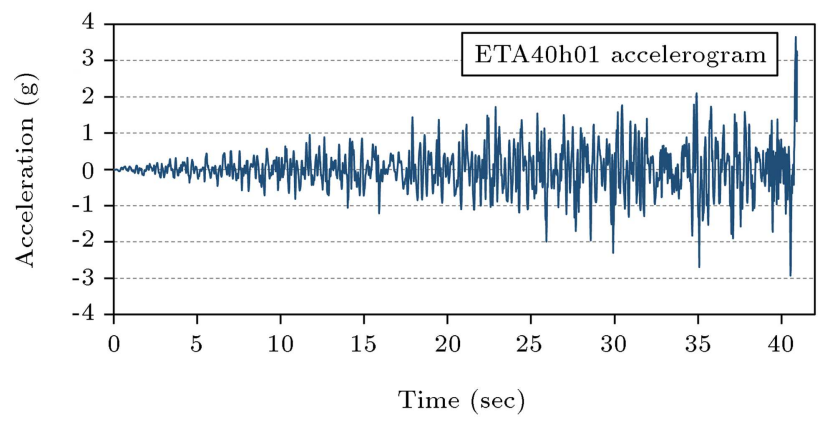

Figure 2. Typical ET record incorporating intensifying dynamic excitation.

numerical investigations remain to be the only practical alternative in order to seek good solutions regarding performance and safety.

In the Endurance Time (ET) method, structures are subjected to a predesigned intensifying dynamic excitation and their performance is continuously monitored as the level of excitation increases [12]. A typical ET Excitation Function (ETEF) is shown in Figure 2. Level of excitation or excitation intensity can be assumed to be any relevant parameter considering the nature of the structure or component being investigated.

Classically, parameters such as Peak Ground Acceleration (PGA) or spectral intensity have been considered most relevant parameters in structural design. More recently, parameters based on input energy, displacement, and damage spectra are also being proposed as a better representative of the dynamic excitation intensity considering structural response. Figure 3 shows the response spectra produced by a typical ETEF at various times. Various ETEFs are publicly available through Endurance Time Method website [13].

While response spectra have been considered to be a standard measure of intensity in producing currently

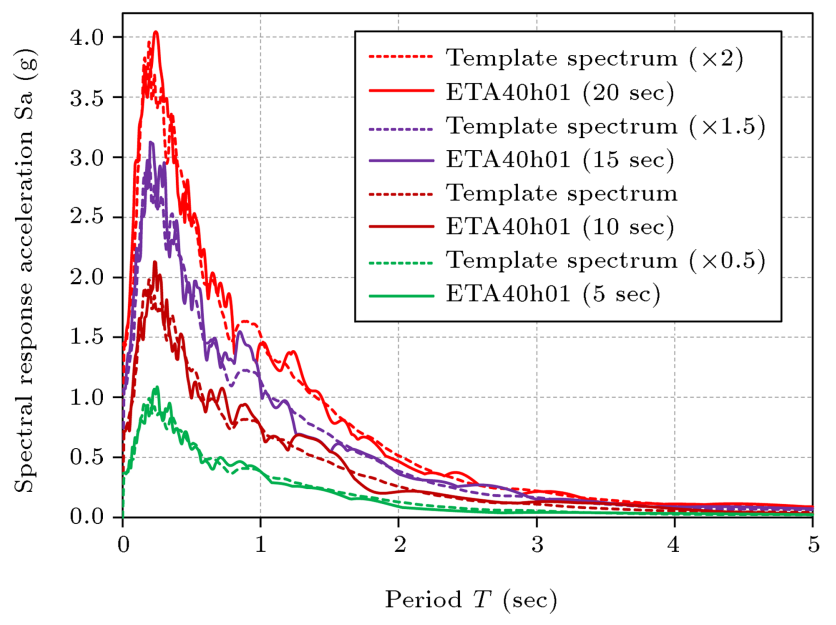

Figure 3. Typical response spectra of ET records at various times (ETA40h01). 
available ETEFs, other intensity measures can also be considered as well. As can be expected, most of these intensity measures correlate with each other and the problem is to choose the best combination of various parameters to achieve better intensifying excitations that can produce better output. Here, the response spectra have been considered as the intensity parameter and ETEF has been produced in such a way that the response spectra produced by each window from time 0 to $t$ are proportional to a template response spectra.

The application of the ET method in performance based design was studied by Mirzaee et al. [14], introducing "ET curve" and the "Target Curve", which respectively express the seismic performance of a structure along various seismic intensities and their limiting values according to code recommendations. Substituting return period or annual probability of exceedance for time in the expression of the performance will make presentation of the results more explicit and will increase their convenience to calculate probabilistic cost [15]. Also, damage levels have been introduced to express the desired damage states in quantifiable terms.

Hazard return period corresponding to a particular time in ET analysis can be calculated by matching the response spectra at effective periods, e.g. from 0.2 to 1.5 times of structure's fundamental period of vibration. The procedure is based on the coincidence of response spectra obtained from the ET accelerogram at different times and response spectra defined for Tehran, at different hazard levels. In Figure 4, a sample target curve and ET curve considering various performance criteria are depicted where ET analysis time has been mapped into return period on horizontal axis. As it can be seen, the structure satisfies the code IO level limitations but it has violated the LS and CP levels limitations, and the frame does not have acceptable performance. As it can be inferred, one of the advantages of ET method is that the performance of the structure in continuous increasing hazard levels can be properly depicted in an easy-to-read figure.

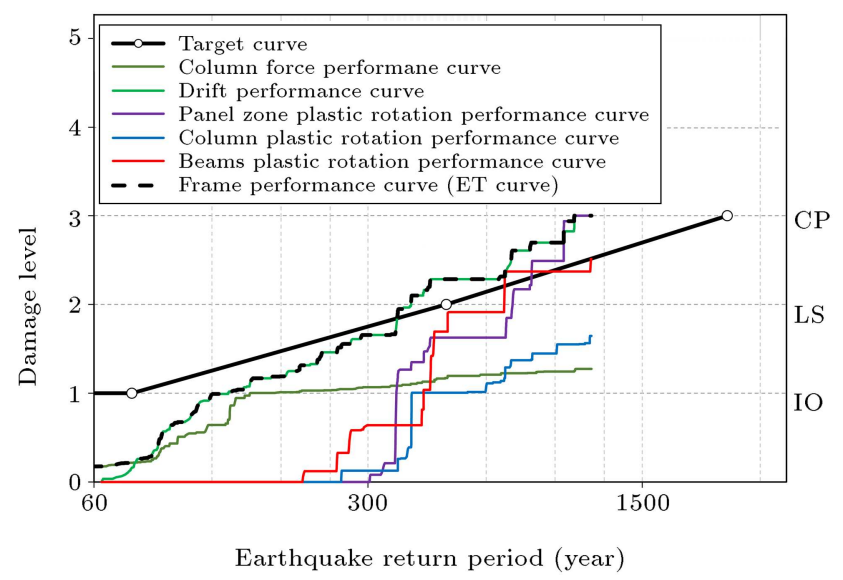

Figure 4. Performance assessment by ET method.

\section{Value based seismic design by the ET method}

Life Cycle Cost Analysis (LCCA) has become an important part of structural engineering to assess the structural comeback and evaluate the performance of the structure in economic terms. It has gained considerable attention of decision making centers to decide on the most cost effective solution related to the construction of structures in seismic regions. LCCA has provided a reliable tool for estimating damage cost due to future earthquakes during the design life of a structure. Instead of "cost" in dollars, in decision making process, any other measure can be used to compare and evaluate design alternatives' expected operations. In this section, the expected total cost imposed by earthquake occurrences during structure's lifespan is selected as an evaluation measure since engineers might be more familiar with this concept. A correlation will be required to express other measures mentioned above, such as downtime or social impacts in economic terms and dollars. By the use of this method, the expected total cost of a structure, including the initial cost and also losses resulting from earthquakes during its lifespan, can be considered as the main indicator of the priority of design alternatives. This analysis, along with an optimization algorithm, can result in a design with the least total cost. LCCA demands the calculation of the cost components that are related to the performance of the structure in multiple earthquake hazard levels. However, these calculations require repetitive and massive analyses of performance assessment and huge computational demand; thus, the involved sophistications may make optimization algorithms impractical, or the used simplifications may decrease the reliability of the outcome. Application of ET method in combination with the concept of LCCA has led to development of a framework for practical Value Based Seismic Design of structures.

ET analysis provides a proper baseline to perform economic analyses on design alternatives with acceptable computational cost. While value can be defined and considered in its broad sense for design purposes, for clarity of the explanation, the structure that is more economical to construct and maintain is considered to be the most valued. Initial construction cost and expected seismic damage cost throughout the lifetime of the structure are usually the two most important parameters for decision making [16]. The cost model used in this study can be found in detail in a work by Basim and Estekanchi [9]. In this model, the total cost, $C_{T O T}$, of a structure can be considered as the sum of its initial construction cost, $C_{I N}$, which is function of design vector, $s$, and the present value of the life cycle cost, $C_{L C}$, which is function of lifetime, $t$, and the design vector [16]. 
Initial cost is the construction and equipping cost of a structure. In our hospital building design example, which is a new moment resisting steel frame, the initial cost is related to the land price, material, and the labor cost for the construction of the structure and equipping costs for health care facilities. The land price and nonstructural components cost are constant for all design alternatives.

To calculate the life cycle cost of the structure, the following cost components are involved: the damage repair cost, the cost of loss of contents due to structural damage quantified by the maximum interstory drift and also floor acceleration, the loss of rental cost, the loss of income cost, the cost of injuries, and the cost of human fatalities $[17,18]$. Interstory drift $(\Delta)$ has been considered as a measure of both structural and non-structural damages and maximum floor acceleration is used to quantify the loss of contents. In this study, seven limit states according to drift ratios based on ATC-13 [19] are used to describe structural performance as shown in Table 1. The relation between floor acceleration values and damage states is shown in Table 1 based on a work by Elenas and Meskouris [20]. The addition of the maximum floor acceleration component in life cycle cost calculation is introduced by Mitropoulou et al. [17]. Piecewise linear relation has been assumed between damage indices and costs [21].
Life cycle cost of the structure is calculated by summing the cost components as follows:

$$
\begin{aligned}
& C_{L C}=C_{d a m}+C_{c o n}+C_{r e n}+C_{i n c}+C_{i n j}+C_{f a t}, \\
& C_{c o n}=C_{c o n}^{\Delta}+C_{c o n}^{a c c}
\end{aligned}
$$

where $C_{d a m}$ is the damage repair cost; $C_{c o n}^{\Delta}$, the loss of contents cost due to structural damage quantified by interstory drift; $C_{\text {con }}^{a c c}$, the loss of contents cost due to floor acceleration; $C_{r e n}$, the loss of rental cost; $C_{i n c}$, the cost of income loss; $C_{i n j}$, the cost of injuries; and $C_{f a t}$, the cost of human fatality. The formulae to calculate each cost component are depicted in Table 2. The values of the mean damage index, loss of function, downtime, expected minor injury rate, expected serious injury rate, and expected death rate used in this study are based on ATC-13 [19] restated in FEMA-227 [22]. Table 3 provides these parameters for each damage state.

As described in [9], the annual rate that any cost component exceeds a threshold value is calculated using the PEER framework. This will result in a curve with cost values in horizontal axis and annual rate of exceedance in vertical axis known as "Loss Curve" [23]. In Figure 5, a sample loss curve due to damage cost is depicted. The area under the loss curve represents the

Table 1. Drift ratio and floor acceleration limits for damage states.

\begin{tabular}{cccc}
\hline $\begin{array}{c}\text { Performance } \\
\text { level }\end{array}$ & $\begin{array}{c}\text { Damage } \\
\text { states }\end{array}$ & $\begin{array}{c}\text { Drift ratio limit (\%) } \\
\text { ATC-13 [19] }\end{array}$ & $\begin{array}{c}\text { Floor acceleration limit (g) } \\
\text { Elenas and Meskouris }[\mathbf{2 0}]\end{array}$ \\
\hline I & None & $\Delta \leq 2$ & $a_{\text {floor }} \leq 0.05$ \\
II & Slight & $0.2<\Delta \leq 0.5$ & $0.05<a_{\text {floor }} \leq 0.10$ \\
III & Light & $0.5<\Delta \leq 0.7$ & $0.10<a_{\text {floor }} \leq 0.20$ \\
IV & Moderate & $0.7<\Delta \leq 1.5$ & $0.20<a_{\text {floor }} \leq 0.80$ \\
V & Heavy & $1.5<\Delta \leq 2.5$ & $0.80<a_{\text {floor }} \leq 0.98$ \\
VI & Major & $2.5<\Delta \leq 5$ & $0.98<a_{\text {floor }} \leq 1.25$ \\
VII & Destroyed & $5.0<\Delta$ & $1.25<a_{\text {floor }}$ \\
\hline
\end{tabular}

Table 2. Formulae for cost components calculation in Dollars [16,18,19].

\begin{tabular}{lcc}
\hline \multicolumn{1}{c}{ Cost component } & Formula & Basic cost \\
\hline Damage repair $\left(C_{\text {dam }}\right)$ & Replacement cost $\times$ floor area $\times$ mean damage index & $500 \$ / \mathrm{m}^{2}$ \\
Loss of contents $\left(C_{\text {con }}\right)$ & Unit contents cost $\times$ floor area $\times$ mean damage index & $250 \$ / \mathrm{m}^{2}$ \\
Loss of rental $\left(C_{r e n}\right)$ & Rental rate $\times$ gross leasable area $\times$ loss of function time & $20 \$ / \mathrm{month}^{2} / \mathrm{m}^{2}$ \\
Loss of income $\left(C_{i n c}\right)$ & Income rate $\times$ gross leasable area $\times$ down time & $300 \$ /$ year $/ \mathrm{m}^{2}$ \\
Minor injury $\left(C_{i n j, m}\right)$ & Minor injury cost per person $\times$ floor area $\times$ occupancy rate & $2000 \$ /$ person \\
Serious injury $\left(C_{i n j, s}\right)$ & $\begin{array}{c}\times \text { expected minor injury rate } \\
\text { Serious injury cost per person } \times \text { floor area } \times \text { occupancy rate }\end{array}$ & $20000 \$ /$ person \\
Human fatality $\left(C_{f a t}\right)$ & Human fatality cost per person $\times$ floor area $\times$ occupancy rate & $300000 \$ /$ person \\
\hline
\end{tabular}


Table 3. Damage state parameters for cost calculations [19,22].

\begin{tabular}{lcccccc}
\hline Damage states & $\begin{array}{c}\text { Mean } \\
\text { damage } \\
\text { index (\%) }\end{array}$ & $\begin{array}{c}\text { Expected minor } \\
\text { injury } \\
\text { rate }\end{array}$ & $\begin{array}{c}\text { Expected } \\
\text { serious } \\
\text { injury rate }\end{array}$ & $\begin{array}{c}\text { Expected } \\
\text { death } \\
\text { rate }\end{array}$ & $\begin{array}{c}\text { Loss of } \\
\text { function } \\
\text { time (days) }\end{array}$ & $\begin{array}{c}\text { Down } \\
\text { time } \\
\text { (days) }\end{array}$ \\
\hline (I)-None & 0 & 0 & 0 & 0 & 0 & 0 \\
(II)-Slight & 0.5 & 0.00003 & 0.000004 & 0.000001 & 1.1 & 1.1 \\
(III)-Light & 5 & 0.0003 & 0.00004 & 0.00001 & 16.5 & 16.5 \\
(IV)-Moderate & 20 & 0.003 & 0.0004 & 0.0001 & 111.8 & 111.8 \\
(V)-Heavy & 45 & 0.03 & 0.004 & 0.001 & 258.2 & 258.2 \\
(VI)-Major & 80 & 0.3 & 0.04 & 0.01 & 429.1 & 429.1 \\
(VII)-Destroyed & 100 & 0.4 & 0.4 & 0.2 & 612 & 612 \\
\hline
\end{tabular}

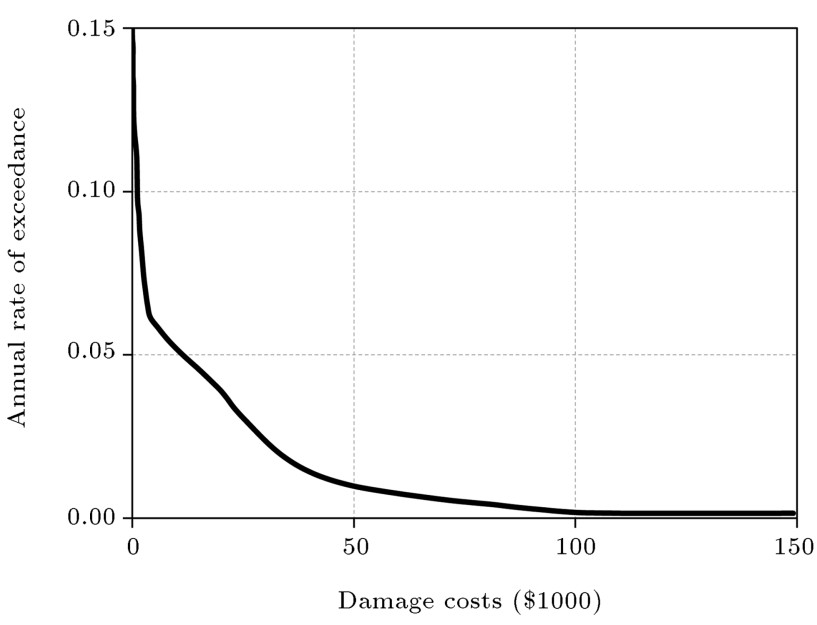

Figure 5. A typical loss curve for the 3-story frame.

mean annual component cost caused by all earthquakes in one year. Life cycle cost of the building is the present value of the annual damage costs summed up through the lifetime of the structure. A discount rate equal to $3 \%$ over 50 years of life of the building has been considered to transform the damage costs to the present value. The total cost of the structure is calculated by summing the initial cost and the life cycle cost and is used as the objective function in optimization algorithm seeking a design with the least total cost.

\section{Case study: 3-story steel moment frame}

In order to demonstrate the method, a three-story and one-bay steel special moment frame used as a hospital building is optimally designed according to Iranian National Building Code (INBC), which is almost identical to the ANSI/AISC360 [24] LRFD design recommendations. Also, the frame is designed optimally to conform to FEMA-350 [10] limitations as performance based design criteria, and as a third step, new design sections have been acquired through the value based design method to have the minimum total cost during its lifetime that is assumed to be
50 years. The performance of the designed frames is investigated by the ET method. For the value based design, the total cost of the structure is selected as the optimization objective to be minimized. An initial cost equal to $\$ 500$ per $\mathrm{m}^{2}$ over the $300 \mathrm{~m}^{2}$ total area of the structure for the prescriptive design is considered and for other design alternatives, it will be calculated according to their steel weight difference by a material plus labor cost of $2 \$ / \mathrm{kg}$. Occupancy rate is taken 10 persons per $100 \mathrm{~m}^{2}$.

Structural response history analyses were performed in OpenSees [25]. Genetic Algorithm (GA) has been used to find the optimum design. Alternative designs should meet some initial constraints. One of the constraints is strong column and weak beam criterion, which should be checked and the other constraint that should be considered before the analysis phase is that the selected sections for columns in each story should not be weaker than the upper story. Besides these constraints, all AISC 360 checks must be satisfied for the gravity loads. Once the expressed constraints are satisfied, the LCC analysis is performed. Genetic algorithm with an initial population size of 100 leads to an optimum design after about 1800 ET response history analyses.

The resultant prescriptive, performance based, and value based designs of the frame are different due to their distinct basic design philosophies. Design sections for each method are depicted in Figure 6. Seismic performance of each design of the frame is shown in Figure 7 . It can be seen that for the value based design, the structure satisfies performance limitations of FEMA-350 with a margin that is justified by economic concerns.

\section{Quantification of resiliency}

Resilience can be quantified using a function which presents the ability of the system to sustain its functionality over a period of time. Such a function for a system, which has exposed an external shock, is presented in Figure 8. The system can be a building, 


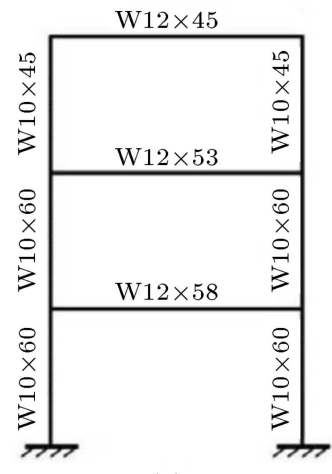

(a)

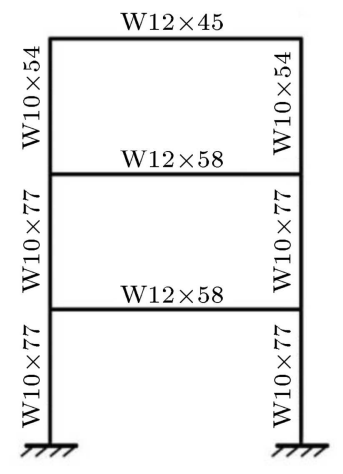

(b)

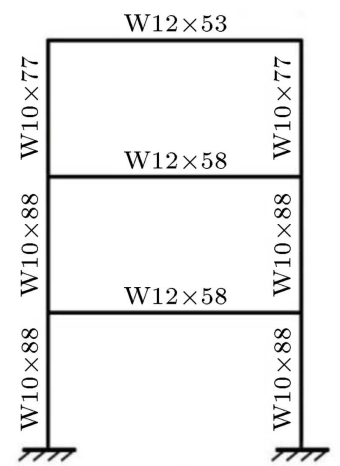

(c)

Figure 6. Frame design results after optimization: (a) Codified design; (b) performance based design; and (c) value based design (least LCC).

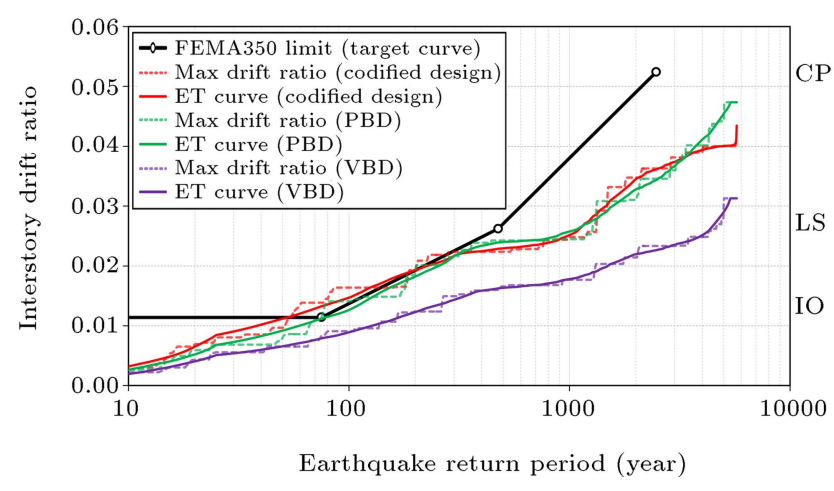

Figure 7. Comparison of responses of the frames at various hazard levels.

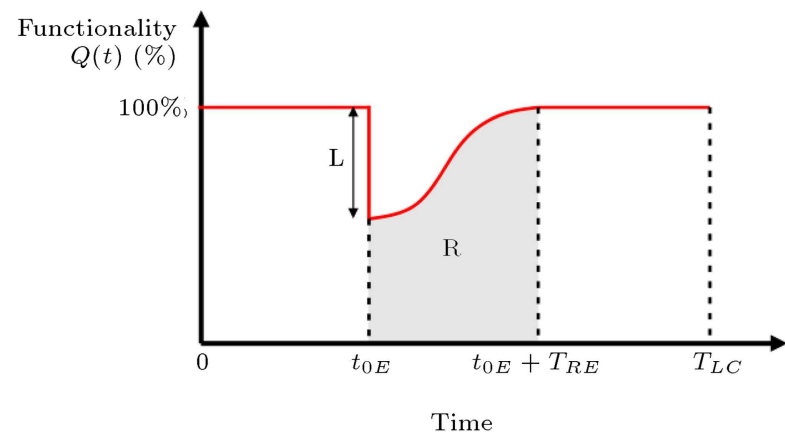

Figure 8. Schematics of a functionality function for a system.

infrastructure, lifeline networks, or a whole community. In this figure, the normalized functionality, $Q(t)$, of the system is traced during a control time, $T_{L C}$, which may be the lifetime of a construction. It is assumed that a disastrous event occurs in a time, $t_{0 E}$, and it takes a period of time, $T_{R E}$, as recovery time in which the system regains its full functionality.

Although the final functionality of the system may differ from the initial functionality, it is assumed here that the recovery process restores the under-study building to its initial condition. For a construction under seismic hazards, $T_{R E}$ depends on many external parameters such as hazard intensities, induced damages, management quality, and resources to repair damages. Many uncertainties are involved in the required recovery time and also the amount of loss of functionality in the case of an event. The recovery time is known to be the most difficult quantity to predict in this function.

A resilience measure should represent the all dimensions of resilience, which include the amount of direct and indirect losses and also the rapidity of recovery process. According to MCEER (multidisciplinary center of earthquake engineering to extreme event) terminology, resilience is quantified as the area under the functionality curve $Q(t)$ of a system. This measure can be considered as a somehow comprehensive Decision Variable (DV) to evaluate the performance of a construction $[5,8]$. Resilience can be formulated by the following formula as a dimensionless parameter in percentage [5]:

$$
\begin{aligned}
& R=\int_{t_{0 E}}^{t_{0 E}+T_{R E}} Q(t) / T_{R E} d t \\
& Q(t)= 1-L\left(1, T_{R E}\right) \\
& {\left[H\left(t-t_{0 E}\right)-H\left(t-\left(t_{0 E}+T_{R E}\right)\right)\right] } \\
& \times f_{R e c}\left(t, t_{0 E}, T_{R E}\right),
\end{aligned}
$$

$L\left(1, T_{R E}\right)$ is the loss function; $f_{R e c}\left(t, t_{0 E}, T_{R E}\right)$ is the recovery function; and $H$ is the Heaviside step function. Other used parameters have been defined previously. Rapidity in the recovery process can be represented by the slope of the functionality curve $(d Q(t) / d t)$. The amount of resources and the quality of management and many other parameters will affect the shape and the slope of the recovery curve and the recovery time, $T_{R E}$. The other dimension of resilience thought to be important in recovery capacity of a system is robustness. It is usually taken as the residual functionality after a disastrous event and in the framework discussed 
by Cimellaro et al. [5] is considered as $1-\bar{L}\left(m_{L}, \alpha \sigma_{L}\right)$ where $\bar{L}$ is a random variable with the mean $m_{L}$ and the standard deviation $\sigma_{L}$, and $\alpha$ is a multiplier of the standard deviation corresponding to a specific level of losses. Here, for simplicity of the representation, the estimation of the resilience $R$ is based on the mean values of $L$. Uncertainties can be modeled using a Monte Carlo approach or reliability methods [2].

The loss model used in this section is similar to that of the previous section. Of course many uncertainties are involved in these losses and various probabilistic loss estimation methods are proposed in the literature. For simplicity of presentation, a somehow simple loss model with limited uncertainty calculations is used here. The method has the capability to use more detailed loss estimation techniques. Total loss, $L$, in this framework can be considered as a function of earthquake intensity, $I$, and recovery time, $T_{R E}$, as it contains both direct losses, $\left(L_{D}\right)$ and indirect losses, $\left(L_{I}\right)$. The later losses can be directly affected by the recovery time. Each of direct and indirect losses has two subcategories as economic losses and casualties losses. Therefore, total loss, $L\left(I, T_{R E}\right)$, consists of four contributions: direct economic losses, $L_{D E}$, direct casualties losses, $L_{D C}$, indirect economic losses, $L_{I E}$, and indirect casualties losses, $L_{I C}$. In this context, direct economic losses, $L_{D E}$, is considered as the sum of damage repair cost and loss of contents cost as a ratio of the total building replacement cost. Thus, $L_{D E}$ is a function of intensity $I$. More detailed loss models using fragilities can be used by the formulation presented in the work by Cimellaro et al. [5].

Direct casualties losses, $L_{D C}$, are calculated as a ratio of the instantaneous number of injured or dead people, $N_{i n}$, to the total number of occupants, $N_{t o t}$. This parameters can also be calculated using the model defined in the previous section:

$$
L_{D C}(I)=\frac{N_{i n}}{N_{t o t}}
$$

The indirect economic losses may be significant for lifeline systems or any critical facilities, such as healthcare centers. The indirect economic losses $L_{I E}\left(I, T_{R E}\right)$ are related to hazard intensity and also the recovery time. More comprehensive models are required to estimate the post-earthquake losses. Loss of rental and loss of income costs in the used cost model can be considered as components of $L_{I E}$. Some other components may be involved in lifeline systems such as water or gas delivery networks that are much more than direct economic losses.

The indirect casualties losses, $L_{I C}\left(I, T_{R E}\right)$, may be significant for a healthcare center. These losses are caused by the hospital dysfunction in recovery time after an earthquake. In this framework, $L_{I C}$ can be calculated as the ratio of the number of injured persons,
$N_{\text {in }}$, to the total population, $N_{t o t}$, served or supposed to be served:

$$
L_{I C}\left(I, T_{R E}\right)=\frac{N_{i n}}{N_{t o t}} .
$$

Casualties' losses will affect the total loss as a penalty function using weighting factors according to the following formulae:

$$
L_{D}=L_{D E} \cdot\left(1+\alpha_{D C} L_{D C}\right), \quad L_{I}=L_{I E} \cdot\left(1+\alpha_{I C} L_{I C}\right),
$$

$\alpha_{D C}$ and $\alpha_{I C}$ are the weighting factors representative of the importance of the occupancy that are determined based on social concerns. The total losses, $L$, is a combination of direct losses, $L_{D}$, and indirect losses, $L_{I}$ :

$$
L\left(I, T_{R E}\right)=L_{D}(I)+\alpha_{I} L_{I}\left(I, T_{R E}\right),
$$

$\alpha_{I}$ is used as a weighting factor to represent the importance of indirect losses to other facilities in community. It is obvious that the more recovery time $T_{R E}$ results in more total loss values. The next step to calculate resilience of the construction is to estimate a recovery path through which the building regains its functionality. This process is complex and is influenced by many environmental conditions, such as quality of management and amount of resources, and may be affected by the amount of disaster consequences in other sectors of the community. The recovery model used in this section is based on the simplified model introduced by Cimellaro et al. [5] with some modifications. Trigonometric function is selected according to the experienced condition in Iran:

$$
f_{r e c}(t)=a / 2\left\{1+\cos \left[\pi b\left(t-t_{0 E}\right) / T_{R E}\right]\right\}
$$

where $a$ and $b$ are constant values; it is assumed here that $a=b=1$. This function is used when the process of recovery starts with considerable delay due to lack of resource or proper management. It is assumed that the structural response to a specific intensity level does not vary in the lifetime of the structure. In other words, deterioration of structural system is ignored for the sake of simplicity. As noted, the structural responses for any hazard intensity are provided through ET analysis. The results are represented via ET curve. The resilience of the studied building in case of hazards with any intensity can be calculated using the presented method.

The resilience, $R$, of each structure, conditional on the occurrence of earthquakes with any intensity, is depicted in Figure 9. In this figure, vertical axis shows the expected resilience of the structure conditional on the occurrence of an earthquake with the annual probability of exceedance presented in horizontal axis. 


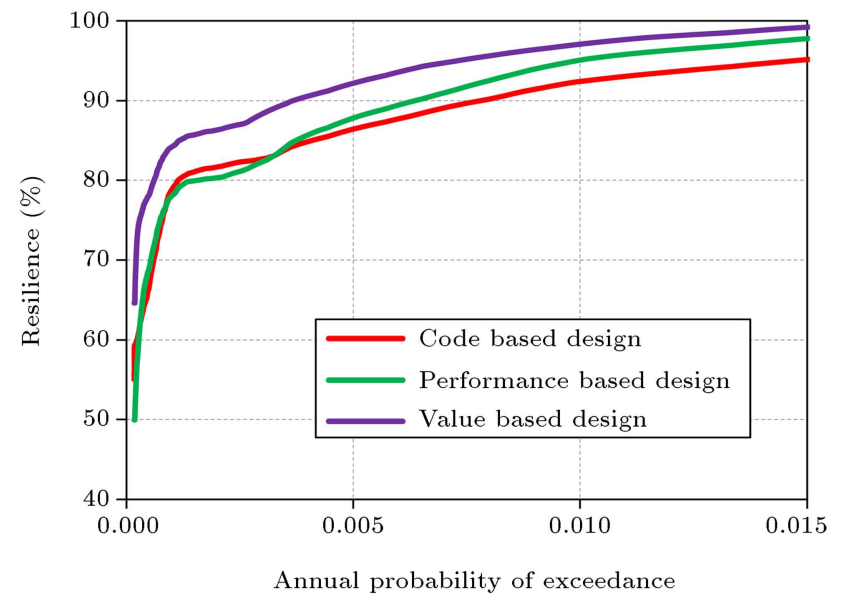

Figure 9. Resilience curve for the 3 structures.

Using the ET method, the resilience of the structure can be explored in a continuous range of intensities. It is obvious that the value based design is the most resilient structure among the 3 alternatives. The reduced computational effort in this framework provides the means to incorporate reliability analyses and account for uncertainties.

\section{Summary and conclusions}

A framework to calculate a resilience measure using the ET method was proposed. A simplified cost and recovery model for a prototype hospital building was developed. Three optimum design alternatives for the structure were considered according to a prescriptive design code, performance based design guideline, and a value based approach. Application of the ET analysis in Life Cycle Cost Analysis (LCCA) has briefly been explained. ET method and the resultant performance curve have provided a proper baseline to calculate the expected damage cost, while the required computational effort is in an acceptable range to be used in conventional optimization techniques. Structural performances of the three structures have been compared using ET curve. A resilience measure according to the current literature was defined and a method to calculate the resilience of the structure conditional on the occurrence of hazard with any intensity was developed. Results were depicted in an easy-to-read figure, introducing "Resilience Curve". Results show that the value based design will have a better performance regarding to the resilience measures. Although the involved uncertainties were not highlighted in this study, the method has the capability to account for them requiring acceptable amount of computational effort.

\section{References}

1. Estekanchi, H., Valamanesh, V. and Vafai, A. "Application of endurance time method in linear seismic analysis", Engineering Structures, 29(10), pp. 25512562 (2007).

2. Basim, M.C. and Estekanchi, H.E. "Application of endurance time method in performance-based optimum design of structures", Structural Safety, 56, pp. 52-67 (2015).

3. Estekanchi, H.E., Basim, M.C. and Vafai, A. "From endurance time to value based seismic design: A path towards seismic resiliency ", Symposia on Resilient Cities, Irvine, CA (2014).

4. Manyena, S.B. "The concept of resilience revisited", Disasters, 30(4), pp. 434-450 (2006).

5. Cimellaro, G.P., Reinhorn, A.M. and Bruneau, M. "Framework for analytical quantification of disaster resilience", Engineering Structures, 32(11), pp. 36393649 (2010).

6. Bruneau, M., Chang, S.E., Eguchi, R.T., Lee, G.C., O'Rourke, T.D., Reinhorn, A.M., Shinozuka, M., Tierney, K., Wallace, W.A. and von Winterfeldt, D. "A framework to quantitatively assess and enhance the seismic resilience of communities", Earthquake Spectra, 19(4), pp. 733-752 (2003).

7. Chang, S.E. and Shinozuka, M. "Measuring improvements in the disaster resilience of communities", Earthquake Spectra, 20(3), pp. 739-755 (2004).

8. Bruneau, M. and Reinhorn, A. "Exploring the concept of seismic resilience for acute care facilities", Earthquake Spectra, 23(1), pp. 41-62 (2007).

9. Basim, M.C., Estekanchi, H.E. and Vafai, A. "A methodology for value based seismic design of structures by the endurance time method", Scientia Iranica, (In press) (2014).

10. FEMA-350 "Recommended seismic design criteria for new steel moment-frame buildings", USA Federal Emergency Management Agency (2000).

11. Sayyah, S. "Report from Bam, Iran: Unkindness of God and lack of care and attention by his sons", http://www.payvand.com/news/04/feb/1110.html (2004).

12. Estekanchi, H.E., Vafai, A. and Sadeghazar, M. "Endurance time method for seismic analysis and design of structures", Scientia Iranica, 11(4), pp. 361-370 (2004).

13. Estekanchi, H.E. Endurance Time Method website, https://sites.google.com/site/etmethod/ (2014).

14. Mirzaee, A., Estekanchi, H.E. and Vafai, A. "Application of endurance time method in performancebased design of steel moment frames", Scientia Iranica, 17(6), pp. 361-370 (2010).

15. Mirzaee, A., Estekanchi, H.E. and Vafai, A. "Improved methodology for endurance time analysis: From time to seismic hazard return period", Scientia Iranica, 19(5), pp. 1180-1187 (2012).

16. Mitropoulou, C.C., Lagaros, N.D. and Papadrakakis, M. "Life-cycle cost assessment of optimally designed reinforced concrete buildings under seismic actions", 
Reliability Engineering \& System Safety, 96(10), pp. 1311-1331 (2011).

17. Mitropoulou, C.C., Lagaros, N.D. and Papadrakakis, M. "Building design based on energy dissipation: A critical assessment", Bulletin of Earthquake Engineering, 8(6), pp. 1375-1396 (2010).

18. Wen, Y. and Kang, Y. "Minimum building life-cycle cost design criteria. II: Applications", Journal of Structural Engineering, 127(3), pp. 338-346 (2001).

19. ATC-13 "Earthquake damage evaluation data for California", Applied Technology Council (1985).

20. Elenas, A. and Meskouris, K. "Correlation study between seismic acceleration parameters and damage indices of structures", Engineering Structures, 23(6), pp. 698-704 (2001).

21. Mirzaee, A. and Estekanchi, H.E. "Performance-based seismic retrofitting of steel frames by the endurance time method", Earthquake Spectra, 31(1), pp. 383-402 (2015).

22. FEMA-227 "A benefit-cost model for the seismic rehabilitation of buildings", Federal Emergency Management Agency, Building Seismic Safety Council, Washington, DC (1992).

23. Yang, T.Y., Moehle, J.P. and Stojadinovic, B., Performance Evaluation of Innovative Steel Braced Frames: University of California, Berkeley (2009).

24. AISC360 "Specification for structural steel buildings (ANSI/AISC 360-10)", American Institute of Steel Construction, Chicago-Illinois (2010).

25. Mazzoni, S., McKenna, F., Scott, M.H., Fenves, G.L. and Jeremic, B., Open System for Earthquake Engineering Simulation (OpenSees), Berkeley, California (2006).

\section{Biographies}

Homayoon Estekanchi is Professor of Civil Engineering at Sharif University of Technology. He received his PhD in Civil Engineering from SUT in 1997, and has been a faculty member at SUT since then. He is a member of Iranian Construction Engineers Organization, ASCE, Iranian Inventors Association, and several other professional associations. His research interests include a broad area of topics in structural and earthquake engineering with a special focus on the design of tall buildings and industrial structures.

Abolhassan Vafai, $\mathrm{PhD}$, is a Professor of Civil Engineering at Sharif University of Technology. He has authored/co-authored numerous papers in different fields of en gineering: applied mechanics, biomechanics, and structural engineering (steel, concrete, timber, and offshore structures). He has also been active in the area of higher education and has delivered lectures and published papers on challenges of higher education, the future of science and technology, and human resources development.

Mohammad Charkhtab Basim is an Assistant Professor of Civil Engineering at Sahand University of Technology. He received his $\mathrm{PhD}$ in Earthquake and Structural Engineering from Sharif University of Technology in 2015. He had been identified as exceptional talent at SUT and is an honorary member of Iranian Construction Engineers Society. His research interests include performance based design of structures, structural reliability and optimization, and rehabilitation methods. 